\title{
Selecting ELL Textbooks: A Content Analysis of L2 Learning Strategies
}

\author{
Jeffrey T. LaBelle \\ College of Education, Marquette University, Milwaukee, Wisconsin, USA \\ Email: jeffrey.labelle@ marquette.edu
}

\begin{abstract}
Although middle school teachers use a variety of ELL textbooks, many lack effective criteria to critically select materials that represent a wide range of L2 learning strategies. This study analyzed the illustrated and written content of 33 ELL textbooks to determine the range of L2 learning strategies represented. The researchers chose an intentional, convenience sample from each textbook to form the corpus they analyzed. They sought to answer the question: To what extent do middle school ELL texts depict frequency and variation of language learning strategies in illustrations and written texts? To measure the content, the researchers developed a coding instrument to track how frequently each of 15 language learning strategies was portrayed. They concluded that 6 of the 33 textbooks had a good to excellent range of L2 learning strategies in both illustrated and written representation. The study provides recommendations for teachers regarding selection of ELL textbooks appropriate for their students along with a sample coding instrument for their use.
\end{abstract}

Index Terms-Learning strategies, English language learners, content analysis, ELL textbooks, English language teaching

\section{INTRODUCTION}

Teachers in middle schools in the city of Milwaukee, much like other American cities, struggle to identify effective and contextually appropriate texts for teaching English to immigrant students (Case, Ndura, \& Righettini, 2005). Relying on a limited number of textbooks available for middle school ELLs, many instructors lack information about the breadth of language learning strategies in these textbooks. By language learning strategies, we mean "the operations or processes which are consciously selected and employed by the learner to learn the TL [Target Language] or facilitate a language task" (White, 2008, p. 8). An analysis of the content of these textbooks would provide one source of data to help teachers in their selection of textbooks for middle school ELL students which would be suitable for their culturally and linguistically diverse students.

From a theoretical perspective, this study established a protocol for the ongoing examination of ELL textbooks currently in use in middle schools. Many classroom instructors rely on their own personal judgment or intuition to select texts for their students or simply depend upon the district-approved textbooks. Some may lack the knowledge and awareness of the extent to which their textbooks represent a variety of L2 learning strategies. We contend that a more critical analysis of textbooks would lend a broader and more detailed description of the learning strategies depicted, as well as raise the consciousness of educators in this regard. The results of our study are intended to assist instructors to make more fully informed judgments in their intentional choices of ELL textbooks.

\section{THEORETICAL FRAMEWORK}

Language learning strategies are of great interest to ELL teachers. In part this can be attributed to their search for the most effective means for their students to learn English. However, because of the great variety and number of L2 learning strategies, teachers frequently find themselves challenged to indentify those strategies which would be most effective in fostering and enhancing student language learning. To that end, we propose that textbooks which include a wide variation and frequency of L2 learning strategies provide ELL teachers with the optimal resource materials for instruction use.

In fact, a wide range of strategies for language learning compete to provide a framework of valuable categories of L2 learning strategies. The most popular schema is utilized by several theorists who divide these strategies into four larger categories: cognitive, metacognitive, social, and affective (Cohen et al., 1996; O'Malley \& Chamot, 1990; Oxford, 1990).

...it is important to emphasize that individual student's learning styles and strategies can work together with---or conflict with---a given instructional methodology. If there is a harmony between (a) the student (in terms of style and strategy preferences) and (b) the instructional methodology and materials, then the student is likely to perform well, feel confident and experience low anxiety. If clashes occur between (a) and (b), the student often performs poorly, lacks confidence, and experiences significant anxiety. (Oxford, 2001a, p. 359) 
To achieve this type of harmony, ELL teachers not only will need to know their students' learning strategies, but also which L2 learning strategies are depicted in the textbooks they use. With this information, instructors can better develop an instructional methodology that will improve student performance and L2 learning outcomes by including a wider range and more complementary balance of language learning strategies.

Most recently Oxford (in press) and Cohen and Macaro (2007) have developed other approaches to language learning strategies that view them not from the perspective of their function, but rather recognize the ways in which the differences between types is blurred. They refer to the multiplicity of strategies that can be in use concurrently, as well as the ways in which strategies interplay with one another to form the over all L2 learner strategy. Furthermore, in the practical realm any single strategy may take on one of these functions for a short time and then suddenly take on another within seconds. In short, a strategy's function might indeed be a moving target.

So, just what are these language learning strategies? Oxford (2001a) provided a fairly reasonable operational definition: "L2 learning strategies are specific behaviors or thought processes that students use to enhance their own L2 learning" (p. 362). However, her analysis of the types of L2 learning strategies was rather complex. Oxford (2001a) cited six major groups of L2 learning strategies: cognitive, metacognitive, memory-related, compensatory, affective, and social (pp. 364-365). In yet another publication, Oxford (2001b) attempted to clarify that these six groups are not so distinct due to variations on the part of the learner:

Major varieties of language learning strategies are cognitive, mnemonic, metacognitive, compensatory (for speaking and writing), affective and social. Theoretical distinctions can be made among these six types; however, the boundaries are fuzzy, particularly since learners sometimes employ more than one strategy at a time. (p. 167)

Approaching L2 learning strategies from another perspective, we might note that a number of researchers have discovered that, as L2 proficiency increases, so also does strategy use (O’Malley \& Chamot, 1990; Oxford, 1996). "If strategy use and language proficiency are related, how can we improve learners' strategy use? Strategy instruction offers interesting possibilities" (Oxford, 2001b, p. 170). I would add: so too does the choice of and content of resource materials. For this very reason, the current study sought to identify content which exhibited illustrated or written indicators of certain language learning strategies. These indicators provide the range of context and content that reflect the variety of student language learning strategies. Teachers would do well to choose those texts which they judge most appropriately fit the language learning strategies in their particular social contexts. Ellis (2004) pointed this out quite succinctly in setting forth the basic tenets of an individual difference theory for language learners:

The theory will need to acknowledge the situated nature of L2 learning. That is, it must reflect the fact that the role of the individual learner factors is influenced by the specific setting in which learning takes place and the kinds of tasks learners are asked to perform in the L2. (pp. 546-547)

In short, L2 language learners are influenced by four key factors: ethnicity, situational context, language learning strategies, and instructional approaches.

On another note, Oxford (2001b, pp. 170-171) cites eight different factors that influence strategy use: motivation, language learning environment, learning style and personality type, gender, culture or national origin, career orientation, age, and nature of the language task.

A given learning strategy is neither good nor bad; it is necessarily neutral until it is considered in the student's context. A strategy is useful under these conditions: (a) the strategy relates well to the L2 task at hand, (b) the strategy fits the particular student's learning style preferences to one degree or another, and (c) the student employs the strategy effectively and links it with other relevant strategies. (Ehrman, Leaver, \& Oxford, 2003, p. 315)

In fact, motivation, the first factor that Oxford (2001b) noted as having an influence on strategy use, became a central focus of a recent volume edited by Dörnyei and Ushioda (2009). In this latest study, motivation is perceived as a crucial element in the development of a L2 self-identity. Strengthening the student's self-identity can, in turn, bolster the achievement of learning outcomes.

Drawing from strategy systems developed by Oxford (1990) and O’Malley and Chamot (1990), Dörnyei (2005) proposes the following typology. Caution should be exercised when using these types, since a great deal of shifting can occur between these them with regard to the exact same strategy,. One example would be when deciding when or how to break into a conversation so as not to be excluding from the discussion. This kind of strategy might apply to all four types or functions categorized here.

1. Cognitive strategies, involving the manipulation or transformation of the learning materials/input (e.g., repetition, summarizing, using images).

2. Metacognitive strategies, involving higher-order strategies aimed at analyzing, monitoring, evaluating, planning, and organizing one's own learning process.

3. Social strategies, involving interpersonal behaviors aimed at increasing the amount of L2 communication and practice the learner undertakes (e.g., initiating interaction with native speakers, cooperating with peers).

4. Affective strategies, involving taking control of the emotional (affective) conditions and experiences that shape one's subjective involvement in learning. (p. 100)

From the preceding review of literature, we can see the great variation in L2 learning strategies. Nevertheless, the research coincides on several key concepts that affect the present study. These are quite readily summarized in Dörnyei’s (2005) four categories as just delineated: cognitive, metacognitive, social, and affective strategies. Further, 
the literature underscores the importance of social context and situation as key to understanding appropriate and effective teaching methodologies to tap into these L2 learning strategies.

\section{RESEARCH QUESTION}

In our analysis of the ELL textbooks, we sought to determine the extent to which the selected corpus exhibited content which included a diverse range of L2 learning strategies including ones from all four functions. The results of this content analysis provide a resource to ELL instructors in selecting textbooks that appeal to the wide range of L2 learning strategies needed in ELL classrooms. In short, this research study sought to answer the following question: To what extent do middle school ELL texts depict frequency and variation of language learning strategies in illustrations and written texts?

The purpose of this study was to determine the frequency and variation of language learning strategies portrayed in ELL middle school textbooks which are used in Milwaukee Catholic and public schools. Our goal was to provide middle school teachers with more criteria to assist them in the selection of textbooks they deem appropriate for their particular classrooms. Fifteen different language learning strategies were coded in a content analysis of chapter 3 or unit 3 of each text in the corpus. For purposes of this study, language learning strategies are defined as "the operations or processes which are consciously selected and employed by the learner to learn the TL [Target Language] or facilitate a language task" (White, 2008, p. 8).

\section{METHOD}

The researchers chose content analysis as the research method for this study because it could most effectively review the frequency and variation of types of L2 learning strategies. Weber (1990) indicates that "Content analysis is a research method that uses a set of procedures to make valid inferences from text" (p. 9). As simple as that may sound, it must be noted that content analysis enjoys a wide range of techniques and applications in the social sciences. Some researchers contend that content analysis is a more quantitative approach, while others view it as necessarily qualitative due to its tendency to use induction in drawing conclusions and recommendations for further research. However, George (2009) insists:

Researchers have long debated the respective merits of "quantitative" and "qualitative" approaches to content analysis...Most writers on content analysis have made quantification a component of their definition of content analysis. In effect, therefore, they exclude the qualitative approach as being something other than content analysis. (p. 144)

In spite of these divergent and contrastive views, the foremost proponents of this type of method (Weber, 1990; Neuendorf, 2002; Krippendorff, 2004) build their definitions upon Berelson's (1952) definition of content analysis as "...a research technique for the objective, systematic, and quantitative description of the manifest content of communication" (p.18). Weber (1990) adds that this method "...uses a set of procedures to make valid inferences from text" (p. 9). Clearly, his definition underscores the inductive aspects of this method. Neuendorf (2002) posits that this is a "scientific method... and is not limited as to the types of variables that may be measured or the context in which the messages are created or presented" (p. 10). In essence, Krippendorff (2004) concurs with Neuendorf (2002), at the same time emphasizing the importance of "....making replicable and valid inferences from texts (or other meaningful matter) to the contexts of their use" (p.18). This distinction points quite nicely to the value of analyzing the content of textbooks actually in use in the Milwaukee middle school context. Finally, it should be noted that crucial to conducting such analysis is the coding which must be done with great care and exactness. To that end, Liamputtong and Ezzy (2005) stress that this type of analysis refers "...to data analysis that involves the identification of categories prior to coding" (pp. 260-261).

Then, just what is the primary purpose of content analysis? George (2009) answers this query quite succinctly:

Quantitative content analysis is, in the first instance, a statistical technique for obtaining descriptive data on content variables. Its value in this respect is that it offers the possibility obtaining more precise, objective, and reliable observations about the frequency with which given content characteristics occur either singly or in conjunction with one another. In other words, the quantitative approach substitutes controlled observation and systematic counting for impressionistic ways of observing frequency of occurrence. (p. 144)

This purpose fits the present study's goal of precise coding the frequency of L2 learning strategies in the content of a series of ELL textbooks. Such "controlled observation and systematic counting" help quantify the frequency and variation with which these strategies occur rather than presenting anecdotal analysis that is extremely subject to the impressions of the researchers.

Since such a wide range of diverse language learning strategies exist in the literature, only those language learning strategies which relate to listening and reading skills were coded. These dealt primarily with comprehension and memory strategies as adapted from Orwig (1999). We chose the particular strategies listed below for their clarity and simplicity to provide a paradigm that would enable the researchers to code quickly, precisely, and efficiently. These 15 strategies provide a broad range of possible cognitive and metacognitive categories rather than social and affective ones. We chose to focus our attention on these two categories because ELL textbooks in general lack sufficient social and affective strategies, so that analysis of them would prove rather unproductive. In addition, not all of the 15 strategies 
analyzed are as frequently activated by ELL students at this particular developmental stage (10- to 14-year-old). Some variation of cognitive development is present as these children move between the concrete operational to the formal operational stages (Piaget, 1971). Still, we have analyzed the content of the corpus for all 15 categories to more thoroughly examine the range of possible strategies available to the middle school ELL students in general.

A. Comprehension strategies

1. Selective Attention: Focus attention on only certain items.

2. Inference: Draw inferences from text or pictures.

3. Top-down Processing: Grasp new information by an overarching framework.

4. Deduction: Draw conclusions based on previous learning.

5. Analysis: Asks student to break apart chunks or utterances.

6. Transfer: Apply previous strategy to new application.

B. Memory strategies

7. Word Association: Make one-to-one connection between words.

8. Visual Association: Link illustrations with words.

9. Action Association: Link visual activities with words.

10. Grouping: Organize words, utterances, or chunks in similar groups.

11. Imagery: Visualize an image that links up several words, utterances, etc.

12. Contextualization: Organize vocabulary, utterances, around a situation.

13. Repetition: Recall words or utterances again and again.

14. Recombination: Reframe or reorganize sets of words, utterances, chunks, etc.

15. Structured Review: Recall information by units, chapters, or other segments.

In order to carry out the content analysis and gather data regarding L2 learning strategies, the researchers conducted a pilot study to solicit feedback for validity. The panel for this pilot study consisted of three graduate students and three faculty members, which included both researchers in the study. This panel of field practitioners and academicians was asked to review the initial coding instruments to determine if the instruments validly measure the content of a sample text for the indicated theme. Feedback from the members of the validity panel was then incorporated into the final coding instruments (Appendix A) which were later used to conduct the actual content analysis reported here. The researchers strove to make these coding instruments as clear and thorough as possible. "The goal in creating codebooks and coding forms is to make the set so complete and unambiguous as to almost eliminate the individual differences among coders" (Neuendorf, 2002, p. 132).

Because coding is done individually, it is imperative that sufficient orientation take place. However, "Final coding is to be done by each coder individually; at this stage, it is not a consensus-building process. Consensus is useful only during training, pilot, and revision stages" (Neuendorf, 2002, p. 133). Ultimately, some variation and divergence of judgment will result in spite of the great care taken to achieve consensus during the first phases of the pilot project.

To that end, the validity panel expressed several concerns and recommendations to the researchers in order to improve the validity of the instrumentation for ethnicity. The panel recommended care should be taken when drawing conclusions or inferences from these categories. Another asked for clarification as to whether the coder should mark one occurrence for each person depicted or consider the photo as whole. "The validity of the coding process is the degree to which the theoretically relevant features of the answers are represented in the codes" (Hak \& Bernts, 2009, p. 221). The panel's recommendations were incorporated into the techniques employed by the coders in analyzing the content of the corpus. The researchers then conducted a pilot reliability assessment "on a randomly selected subsample of the total sample message pool before the study [began] in earnest" (Neuendorf, 2002, p. 146).

Finally, the researchers met in May 2008, to participate in a two-hour training session in which they practiced coding a sample corpus taken from a segment of the Access English text other than the third chapter or unit. The researchers' coding consisted of placing a mark in ink by hand for each occurrence of the L2 learning strategy indicated in the coding instruments when analyzing either illustrations or text for that particular category. They discovered and made clarifications regarding the definitions of the various language learning strategies developed in the coding instrumentation. The researchers met weekly over the course of two months to discuss any further concerns in the interpretation of the coding instruments and to clarify any differences to ensure inter-coder reliability, that is "...the amount of agreement or correspondence among two or more coders" (Neuendorf, 2002, p. 141). In essence, inter-coder reliability is much more readily determined than validity because it is based upon "... whether a coding of an answer is identical to another coding of the same answer, whether done at another time by the same coder or at the same time by another coder...Reliability is a matter of computation" (Hak \& Bernts, 2009, p. 221).

For this reason, special care was taken in the training of coders as well as the communication between the coders to ensure accurate computation of frequency and variation of language learning strategies exhibited in both illustrations and written texts. In addition, the coders were meticulous in applying the instructions as set forth in the coding instruments reviewed by the validity panel. These measures were taken to enhance and improve the reliability of the coders as indicated by Hak and Bernts (2009) who recommend "reliability can be improved by...coding in pairs of coders, developing more detailed instructions, selecting professional coders (e.g., the researcher's colleagues or graduate students) and, last but not least, coder training" (p. 222). 
To select the sample corpus for content analysis, the researchers first collected copies of all the 64 ELL texts used in eight middle school classrooms. These texts represent a variety of ELL texts that include academic content areas such as mathematics, science, social studies, and language arts at the introductory, intermediate, and advanced levels of English language learning. Then, they selected from these texts only those that were actual student textbooks, excluding teacher manuals, teacher editions, student workbooks, and trade books. From the 64 representative books, 33 were chosen as appropriate for the study based upon their scope, i.e., actual student texts in contrast to student workbooks or teacher editions. Of particular note was the Access series that all eight middle schools utilized. (A complete listing of these 33 textbooks analyzed can be found in Appendix B).

The results of this sorting process were 33 textbooks from which the corpus under study was derived. Depending on how each textbook was organized (by chapters or units), the content analysis was conducted on the third chapter or unit of each of the 33 representative textbooks as a systematic, convenience sample. Taken together, these chapters or units formed the corpus of the study. The researchers gather the data regarding language learning strategies by means of a self-designed coding instrument consisting of 15 categories, one for each type of language learning strategy (Appendix A). The coding was conducted in two parts: first, language learning strategies as exhibited in illustrations; second, language learning strategies as exhibited in written text. The purpose of this two-part procedure was twofold: 1) to gather data to independently in illustrated and written depiction and 2) to underscore the importance of both representations and their impact on the L2 learner. Coding was based upon each researcher's judgment of his or her observations and interpretations of the photos, drawings, illustrations, or actual narrative texts within the corpus chosen for consideration.

The two researchers each coded either 16 or 17 of the textbooks (for a total of 33) that formed the corpus by using the original copies of the textbooks, printed instrumentation sheets, and marked the occurrences of types of L2 learning strategies depicted in chapter 3 or unit 3 of that particular textbook. Once the coder finished an individual third chapter or unit of a textbook, he or she moved on to the next textbook. This coding was conducted over a period of two months, in June and July, 2008.

What makes the use of content analysis so appropriate to this particular study is its contextual applicability. Krippendorff (2004) maintains that "Content analysis is a research technique for making replicable and valid inferences from texts (or other meaningful matter) to the contexts of their use" (p. 18). That is why the purpose of our analysis of ELL middle school textbooks was not merely to determine the frequency and variation of L2 learning strategies exhibited in the books, but also to provide ELL teachers with information that will help them to select textbooks they deem appropriate for their students. Presumably ELL instructors are dedicated to selecting the best textbooks for their students. This study yields identifies cognitive and metacognitive L2 learning strategies that are readily accessible in these textbooks. ELL teachers most likely will desire to choose textbooks that match the particular L2 learning strategies of their students to improve language learning.

After completing the coding of all 33 textbooks, we then tallied the total number of occurrences of each type of L2 learning strategy and organized the data reports to display raw totals for the textbooks across the 15 strategies. Tables 1 and 2 only list those textbooks ranked as excellent or good based upon the following rubric that measured the range (frequency + variation) of depiction of L2 learning strategies:

1. Extensive: $>50$ frequencies $+>12$ strategies represented

2. Considerable: $26-50$ frequencies $+9-12$ strategies represented

3. Some: $11-25$ frequencies $+7-8$ strategies represented

4. Little: 1-10 frequencies and/or 1-6 strategies represented

5. None: 0 frequency; 0 strategies represented

\section{RESUlts}

In general terms, the results of our content analysis indicate that 6 of these textbooks exhibited considerable to extensive diversity of L2 learning strategies in both illustrations and written texts (see Tables 1 and 2). These are Access American History, Access English, Access Math, ESL 5, Look, I Can Talk, and Voices in Literature Gold. In illustrated content, the Access series (American History, English, Math, and Science) was particularly noteworthy for its extensiveness of diversity of L2 learning strategies. By diversity of L2 learning strategies, we refer to the frequency of strategies exhibited within each textbook as well as the variation of strategies exhibited. For example, Access English had 97 occurrences of strategies exhibited in illustrations and 201 in written text. In regard to the variation of strategies, Access English had strategies represented for all 15 possible strategies. For this reason, we concluded that Access English exhibits extensive diversity of L2 learning strategies in both illustrations and written text.

On the other hand, several of the textbooks analyzed had none or little variation in L2 learning strategies in illustrations. These included $20^{\text {th }}$ Century American Short Stories, A World of Fiction, Adventures of Tom Sawyer, English Yes! Intermediate, In Good Company, \#3, Pizza Tastes Great!, Readings in Cultural Literacy, and Teen Scene. These rankings were based upon the same schema mentioned previously. However, it is important to recognize that all the textbooks analyzed had some, considerable, or extensive variation of L2 learning strategies in written texts. (See Tables 1 and 2). 
For purposes of ranking the textbooks for range of depiction of L2 learning strategies, we have displayed the results for illustrations and written texts in Tables 3 and 4 respectively. It is quite clear that illustrated representation of L2 learning strategies is much more limited, resulting in only 3 textbooks ranked as extensive and 3 as considerable in range of depiction (that is, frequency + variation) of L2 learning strategies in illustrations. On the other hand, in written texts, 7 textbooks ranked as extensive and 11 as considerable in regard to range of depiction of L2 learning strategies. This difference between illustrated and written depiction would appear to indicate the relative ease with which strategies can be represented in written text versus illustration. (See Tables 3 and 4).

The depiction of strategies refers to either the illustrations or written texts that the coders most closely associated with a particular strategy from among the 15 types as previously defined. These illustrations or written texts attempt to draw upon one or more of the 15 learning strategies. An extensive or considerable range of depiction would allow for greater diversity of learning styles and presumably enhance L2 learning.

TABLE 1

DIVERSITY OF L2 LEARNING STRATEGIES IN ILLUSTRATIONS BY TEXTBOOK

\begin{tabular}{|c|c|c|c|c|c|c|c|c|c|c|c|c|c|c|c|c|}
\hline Title & 1 & 2 & 3 & 4 & 5 & 6 & 7 & 8 & 9 & 10 & 11 & 12 & 13 & 14 & 15 & Total \\
\hline Access American History & 5 & 6 & 13 & 6 & 5 & 4 & 20 & 35 & 13 & 24 & 18 & 24 & 3 & & 3 & 179 \\
\hline Access English & 20 & 6 & 8 & 2 & 5 & 2 & 4 & 10 & 3 & 12 & 5 & 3 & 2 & 1 & 14 & 97 \\
\hline Access Math & 5 & 14 & 8 & 6 & 5 & 3 & 9 & 19 & 10 & 8 & 4 & 18 & 5 & 4 & 1 & 119 \\
\hline ESL 5 & 15 & 5 & 3 & 1 & 3 & 4 & 9 & 12 & 3 & 1 & & & & 1 & 6 & 63 \\
\hline Look, I Can Talk & 3 & 5 & & 9 & & & 6 & 21 & & 2 & 15 & 8 & 8 & 16 & 3 & 96 \\
\hline Voices in Literature, Gold & 4 & 8 & 2 & 1 & 1 & 1 & 1 & 32 & 9 & 1 & 2 & 3 & & & & 65 \\
\hline
\end{tabular}

TABLE 2

DIVERSITY OF L2 LEARNING STRATEGIES IN WRITTEN TEXT BY TEXTBOOK

\begin{tabular}{|c|c|c|c|c|c|c|c|c|c|c|c|c|c|c|c|c|}
\hline Title & 1 & 2 & 3 & 4 & 5 & 6 & 7 & 8 & 9 & 10 & 11 & 12 & 13 & 14 & 15 & Totals \\
\hline Access American History & 19 & 16 & 13 & 8 & 11 & 11 & 6 & 17 & 18 & 7 & 12 & 3 & 4 & 4 & 4 & 153 \\
\hline Access English & 29 & 9 & 3 & 9 & 11 & 4 & 6 & 10 & 3 & 12 & 56 & 6 & 3 & 1 & 39 & 201 \\
\hline Access Math & 2 & 16 & 23 & 12 & 31 & 6 & 9 & 5 & 21 & 2 & 1 & 12 & 6 & 9 & 3 & 158 \\
\hline Access Science & 6 & 2 & 3 & 3 & 5 & & 2 & 4 & 1 & 3 & 3 & 2 & 3 & & 5 & 42 \\
\hline Cause \& Effect & & 5 & 6 & 5 & 6 & 10 & 5 & 1 & 5 & 5 & & 5 & & 10 & 5 & 68 \\
\hline English, Yes! Beginning & & 2 & 2 & 4 & 4 & 1 & 4 & 1 & 4 & 4 & & 4 & 4 & 7 & 8 & 49 \\
\hline English, Yes! Intermediate & 38 & 7 & 14 & 4 & 3 & 3 & 16 & 2 & 10 & 19 & 2 & 7 & 12 & 3 & 41 & 181 \\
\hline English, Yes! Introductory & 31 & 9 & 7 & 4 & 5 & 1 & 12 & 4 & 3 & 5 & 2 & 3 & 2 & & 35 & 123 \\
\hline ESL 5 & 14 & 7 & 5 & 2 & 3 & 4 & 2 & 13 & 4 & 8 & 11 & 12 & & & 14 & 99 \\
\hline Fact \& Figures & 5 & 3 & 1 & 1 & 2 & & 2 & 1 & & 5 & 2 & 6 & 2 & 1 & 3 & 34 \\
\hline High Point & 3 & 1 & 3 & 3 & 2 & 1 & 1 & 13 & 3 & 1 & & 2 & 2 & 1 & & 36 \\
\hline Look, I Can Talk & 13 & 3 & 4 & 1 & 2 & & & 10 & & 5 & & 1 & 2 & 8 & 5 & 54 \\
\hline Pizza Tastes Great! & 3 & 2 & & 3 & 1 & 6 & 3 & 2 & & & 3 & 2 & 1 & 1 & 4 & 31 \\
\hline Teen Scene & 2 & & 1 & 2 & 1 & 5 & 2 & 1 & & 3 & & 3 & 1 & & 5 & 26 \\
\hline Turning Points 4 & 5 & 4 & 6 & 7 & 5 & 2 & 1 & 1 & 1 & 2 & & 4 & 1 & 4 & 1 & 44 \\
\hline Voices in Lit., Bronze & 1 & 2 & & & 8 & 2 & 3 & 6 & 9 & & & 1 & 1 & 2 & 2 & 37 \\
\hline Voices in Literature, Gold & 2 & 5 & 2 & 7 & 12 & 4 & 6 & 1 & 2 & 3 & 6 & 11 & 4 & 8 & 3 & 76 \\
\hline Voices in Literature, Silver & 2 & & 2 & & & 2 & 2 & 1 & & 1 & 3 & 2 & & 2 & 18 & 35 \\
\hline
\end{tabular}


TABLE 3

RANGE OF L2 LEARNING STRATEGIES IN ILLUSTRATIONS BY TEXTBOOK

\begin{tabular}{|c|c|}
\hline Title & Range \\
\hline Access American History & Extensive \\
\hline Access English & Extensive \\
\hline Access Math & Extensive \\
\hline ESL 5 & Considerable \\
\hline Voices in Literature, Gold & Considerable \\
\hline Look, I Can Talk & Considerable \\
\hline Access Science & Some \\
\hline English, Yes! Introductory & Some \\
\hline Voices in Literature, Bronze & Some \\
\hline Voices in Literature, Silver & Some \\
\hline 20th Century Am. Short Stories & Little \\
\hline America's Story & Little \\
\hline Cause \& Effect & Little \\
\hline Content Connection & Little \\
\hline English, Yes! Beginning & Little \\
\hline English, Yes! Intermediate & Little \\
\hline English, Yes! Transitional & Little \\
\hline ESL 4 & Little \\
\hline Fact \& Figures & Little \\
\hline High Point & Little \\
\hline In Good Company, \#3 & Little \\
\hline Living, Learning, Literature & Little \\
\hline Look, I Can Talk More! & Little \\
\hline Pizza Tastes Great! & Little \\
\hline Sam and Pat 1 & Little \\
\hline Sam and Pat 2 & Little \\
\hline Teen Stories & Little \\
\hline Turning Points 3 & Little \\
\hline Turning Points 4 & Little \\
\hline A World of Fiction & None \\
\hline Adventures of Tom Sawyer & None \\
\hline Readings in Cultural Literacy & None \\
\hline Teen Scene & None \\
\hline
\end{tabular}


TABLE 4

RANGE OF L2 LEARNING STRATEGIES IN WRITTEN TEXT By TEXTBOOK

\begin{tabular}{|c|c|}
\hline Title & Range \\
\hline Access American History & Extensive \\
\hline Access English & Extensive \\
\hline Access Math & Extensive \\
\hline English, Yes! Intermediate & Extensive \\
\hline English, Yes! Introductory & Extensive \\
\hline ESL 5 & Extensive \\
\hline Voices in Literature, Gold & Extensive \\
\hline Access Science & Considerable \\
\hline Cause \& Effect & Considerable \\
\hline English, Yes! Beginning & Considerable \\
\hline Facts \& Figures & Considerable \\
\hline High Point & Considerable \\
\hline Look, I Can Talk & Considerable \\
\hline Pizza Tastes Great! & Considerable \\
\hline Teen Scene & Considerable \\
\hline Turning Points 4 & Considerable \\
\hline Voices in Literature, Bronze & Considerable \\
\hline Voices in Literature, Silver & Considerable \\
\hline 20th Century Am. Short Stories & Some \\
\hline A World of Fiction & Some \\
\hline Adventures of Tom Sawyer & Some \\
\hline America's Story & Some \\
\hline English, Yes! Transitional & Some \\
\hline ESL 4 & Some \\
\hline In Good Company, \#3 & Some \\
\hline Living, Learning, Literature & Some \\
\hline Look, I Can Talk More! & Some \\
\hline Readings in Cultural Literacy & Some \\
\hline Sam and Pat 1 & Some \\
\hline Sam and Pat 2 & Some \\
\hline Teen Stories & Some \\
\hline Turning Points 3 & Some \\
\hline
\end{tabular}

\section{CONCLUSIONS}

From the analysis of the data collected, classroom teachers can readily determine which textbooks are most diverse in their L2 learning strategies. Furthermore, this information can assist instructors in making a more informed selection of instructional materials for ELL classes by providing teachers with our ranking of textbooks and a coding instrument which they can use to analyze the content of additional textbooks of their choosing.

In contrast, those textbooks which provide little or no diversity of learning strategies are called into question as to their appropriateness and effectiveness in responding to the wide variety of learning styles of the students. In particular, cultural and linguistic variations make the selection of textbooks more complex and tenuous. Since students in most ELL classrooms come from a variety of cultural and linguistic contexts, a one-size-fits-all approach (one which unfortunately dominates the field), is clearly misguided. One way in which the ELL instructor can improve or enhance L2 learning is by critically selecting textbooks which employ the broadest range of L2 language learning strategies in illustrations and written text. In short, the classroom teacher needs to consider the possibility of choosing textbooks which might scaffold a wider range of learning strategies (Case, Ndura, \& Righettini, 2005). Otherwise, he or she will be faced with constantly searching for materials to supplement the variety of learning styles of the students. This would be a very time-consuming and costly venture indeed.

Finally, classrooms instructors would do well to take a critical view in their analysis of textbooks used to improve L2 learning (Grady, 1997). It would be quite insufficient to rely solely on an analysis of the content of textbooks regarding L2 learning strategies to determine if the themes depicted in textbooks match the lived reality of the ELLs (Gilmore, 
2007). The ultimate goal of appealing to L2 learning strategies should be to maximize the L2 learning of the ELL students. As Rivera-Mills and Plonsky (2007) conclude: "This new perspective to learning strategies training could, in turn, change the fundamental beliefs that students have about learning a language, and even create or reinforce students' motivation for successful language learning" (p. 544). By providing students with ELL textbooks that reflect the widest range of L2 learning strategies, we can more effectively engage and motivate them to learn English.

\section{LIMITATIONS}

Since content analysis involves no human subjects, this particular study has no specific population of participants under investigation. However, it must be noted that the corpus selected for this content analysis represents only a selection of 33 student textbooks in use at the time of the study in eight middle schools in Milwaukee, Wisconsin. Since the corpus did not include all middle school ELL texts currently available in publication and use in the United States, the results of this study cannot be generalized to all ELL textbooks. Rather, the transferability of this study is limited to the schools and textbooks under investigation. Nevertheless, the conclusions and recommendations indicated here may benefit schools and educators in other contexts in the United States who use the same or similar student textbooks.

However, ELL teachers should be cautious to jump to the conclusion that those particular textbooks are the best or most appropriate for their own classrooms. Other factors need to be taken into account. These include, but are not limited to, the ethnic composition of their particular classroom, the demographic context in which the students live, and the teaching methods employed by the instructor of record. In short, the representation of diverse L2 learning strategies in a given textbook does not necessarily mean that a particular textbook is the most appropriate one for a group of students.

Although sample figures, illustrations, or texts have not been displayed in this study for the benefit of the reader, it must be recognized that strategies are often difficult to recognize. The coding of L2 learning strategies in this study was based upon associations made by the coders. These associations are dependent upon the individual researcher's judgment and observation of the selected corpus. To that end, some errors may have occurred due to limitations in perception and judgment.

\section{RECOMMENDATIONS}

Middle school teachers, principals, district or diocesan superintendents, or any who are responsible for ELL textbook adoption should consider the results of this study in making their decisions for ELL textbook selection. Our conclusions indicate 6 textbooks with a considerable to extensive range of depiction of L2 learning strategies. These may very well be appropriate choices for a particular school context. Those who teach and administrate in those contexts will be the most indicated judges of ELL textbooks choice.

ELL teachers and their administrators need to be more fully informed of the L2 learning strategies exhibited in the textbooks they currently use, as well as those they might select for future use. The results of this study provide one source of information to assist them in their decisions. Professional ELL educators would do well to make use of the coding instrument when reviewing other textbooks not included in our content analysis. In any case, ELL teachers need to review their textbooks with a more critical eye and not just cursory or limited view to ensure the selection of materials that more accurately reflect the cultural and linguistic diversity of the ELL students in a given context.

\section{SUGgestions FOR FuRTHER RESEARCH}

Further study is needed to determine what occurs when learners actually attempt to use these recommended textbooks. The scope of the present study was to set up a protocol for analyzing the textbooks themselves. The next stage of research would include observations in actual instructional settings to collect information about the effectiveness of these same textbooks in real pedagogical practice. In addition, more research is needed to study how L2 learning strategies are affected by a variety of factors including ethnicity, situational context, and language teaching methods. It would be beneficial not only to research these factors separately, but also to assess how they interact to enhance or detract from L2 learning. To that end, in separate studies, we have set about to analyze the content of these same 33 textbooks for these other three factors. It is our hope that the combined results of these studies will further our goal of providing middle school teachers with more criteria to assist them in the selection of ELL textbooks they deem appropriate for their particular classrooms.

Some questions remain unanswered at the conclusion of this study. For example, one might question whether the cognitive and metacognitive approaches are the only ways to go in analyzing the content of textbooks. Perhaps a skillsbased or learning vs. usage approach might yield some practical applications to language learning and teaching. Future research that combines all three of these approaches might surface a more holistic view of the ways in which learning strategies and teaching strategies interplay.

Finally, because the present study did not solicit reactions from the L2 learners themselves, it would be enlightening to investigate how students with different learning styles or preferences might respond to these textbooks. Such qualitative research might generate some unique insights to guide further investigations. 
APPENDIX A SAMPLE CODING INSTRUMENTATION

LANGUAGE LEARNING STRATEGIES

CODER:

DATE

BOOK TITLE:

Part 1: Please place a tally mark (I) in the table below to indicate the language learning strategies, appearing in illustrations in the excerpt (these would include boxes or graphics, even if they contain words).

Examples:

1. You see a diagram that analyzes the usage of words in English sentences.

2. You observe a chart that maps out how some words are associated with other words.

You would record your observations as indicated in bold in the table below.

\begin{tabular}{|l|l|}
\hline Language Learning Strategy & Your Observations \\
\hline Selective Attention strategy & \\
\hline Inference strategy & \\
\hline Top-down Processing strategy & \\
\hline Deduction strategy & I (diagram that analyzes usage of words) \\
\hline Analysis strategy & \\
\hline Transfer strategy & I (chart that connects words) \\
\hline The Word Association strategy & \\
\hline The Visual Association strategy & \\
\hline Action Association strategy & \\
\hline The Grouping strategy & \\
\hline The Imagery strategy & \\
\hline The Contextualization strategy & \\
\hline Repetition strategy & \\
\hline Recombination strategy & \\
\hline The Structured Review strategy & \\
\hline
\end{tabular}

Part 2: Please place a tally mark (I) in the table below to indicate the language learning strategies in the text appearing in the excerpt (written data only).

Examples:

1. You read, "Repeat the same process you used in Part I of this chapter."

2. You read, "Follow the directions in this section and then act out the role of the character."

You would record your observations as indicated in bold in the table below.

\begin{tabular}{|l|l|}
\hline Language Learning Strategy & Your Observations \\
\hline Selective Attention strategy & \\
\hline Inference strategy & \\
\hline Top-down Processing strategy & \\
\hline Deduction strategy & \\
\hline Analysis strategy & \\
\hline Transfer strategy & \\
\hline The Word Association strategy & $\begin{array}{l}\text { I “Follow the directions in this section and then act out the role } \\
\text { of the character." }\end{array}$ \\
\hline The Visual Association strategy & \\
\hline Action Association strategy & \\
\hline The Grouping strategy & \\
\hline The Imagery strategy & \\
\hline The Contextualization strategy & \\
\hline Repetition strategy & \\
\hline Recombination strategy & \\
\hline The Structured Review strategy & \\
\hline
\end{tabular}

\section{APPENDIX B TEXTBOOKS ANALYZED}

Ackert, P., Giroux de Navarro, N., \& Bernard, J. (1999). Facts \& figures: Beginning reading practice. Boston: Heinle \& Heinle Publishers. 
Ackert, P., Giroux de Navarro, N., \& Bernard, J. (1999). Cause \& effect: Intermediate reading practice. Boston: Heinle \& Heinle Publishers.

Bernstein, V. (Ed.). (2001). America's story book one to 1865. Austin, TX: Steck-Vaughn Company.

Chamot, A. U., Cummins, J., Kessler, C., \& O'Malley, J. M., Fillmore, L. W. (1997). ESL: Accelerating English language learning. Book 4. Glenview, IL: ScottForesman.

Chamot, A. U., Cummins, J., Kessler, C., \& O'Malley, J. M., Fillmore, L. W. (1997). ESL: Accelerating English language learning. Book 5. Glenview, IL: ScottForesman.

Chips, B., Manzano, B., \& Terrell, T. D. (Eds.). (1987). Content connection. Northvale, NJ: Santillana.

Drayton, A. M., \& Skidmore, C. (1985). In good company: A skill-building reader. Reading, MA: Addison-Wesley Publishing.

Goodman, B. (Ed.). (1996). English, yes! Learning English through literature. Beginning level 1. Lincolnwood, IL: Jamestown Publishers.

Goodman, B. (Ed.). (1996). English, yes! Learning English through literature. Intermediate level 1. Lincolnwood, IL: Jamestown Publishers.

Goodman, B. (Ed.). (1996). English, yes! Learning English through literature. Introductory level 1. Lincolnwood, IL: Jamestown Publishers.

Goodman, B. (Ed.). (1996). English, yes! Learning English through literature. Transitional. Lincolnwood, IL: Jamestown Publishers.

Great Source Education Group. (2005). Access: Building literacy through learning. American History. Wilmington, MA: Houghton Mifflin.

Great Source Education Group. (2005). Access: Building literacy through learning. English. Wilmington, MA: Houghton Mifflin.

Great Source Education Group. (2005). Access: Building literacy through learning. Math. Wilmington, MA: Houghton Mifflin.

Great Source Education Group. (2005). Access: Building literacy through learning. Science. Wilmington, MA: Houghton Mifflin.

Hartel, J., Lowry, B., \& Hendon, W. (Eds.). (2006). Sam and Pat beginning reading and writing 1. Boston: The Thomson Corporation.

Hartel, J., Lowry, B., \& Hendon, W. (Eds.). (2006). Sam and Pat beginning reading and writing 2. Boston: The Thomson Corporation.

Iantorno, G., \& Papa, M. (1994). Turning points: Communicating in English level 3. Reading, MA: Addison-Wesley Publishing Company.

Iantorno, G., \& Papa, M. (1994). Turning points: Communicating in English level 4. Reading, MA: Addison-Wesley Publishing Company.

Kanasky, W. F., Howard, E., \& Graham, P. A. (Eds.). (1993). Living, learning \& literature: Classic and contemporary works. Compton, CA: Santillana.

Koch, K. D., Mrowicki, L., \& Ruttenberg, A. (Eds.). (1988). Teen scene: Personal stories for students who are beginning to read. Palatine, IL: Linmore Publishing, Inc.

Koch, K. D., Mrowicki, L., \& Ruttenberg, A. (Eds.). (1990). Teen stories: Personal stories for students who are beginning to read. Palatine, IL: Linmore Publishing, Inc.

Marcus, S. (Ed.). (2006). A world of fiction: Twenty timeless short stories. White Plains, NY: Pearson Education.

Margulies, S., \& Crowell, C. E. (Eds.). (1997). Readings in cultural literacy: Topics across the curriculum. New York: Educational Design, Inc.

McCloskey, M. L., \& Stack, L. (Eds.). (1996). Voices in literature bronze. Boston, MA: Heinle.

McCloskey, M. L., \& Stack, L. (Eds.). (1996). Voices in literature silver. Boston: Heinle.

McCloskey, M. L., \& Stack, L. (Eds.). (1996). Voices in literature gold. Boston: Heinle.

McConochie, J. A. (Ed.). (1975). 20th century American short stories. New York: Collier MacMillian.

Ray, B. (2000). Look, I can talk! A step-by-step approach to communication through TPR stories. Los Gatos, CA: Sky Oaks Productions, Inc.

Ray, B., Neilson, J., Cline, D., \& Stevens, C. (1998). Look, I can talk more! Student notebook: A step-by-step approach to communication through TPR stories. Los Gatos, CA: Sky Oaks Productions, Inc.

Pickett, W. P. (2002). The pizza tastes great: Dialogs and stories (2nd ed.). White Plains, NY: Pearson Education.

Schifini, A., Short, D., \& Tinajero, J. V. (2000). High point: Success in language, literature, content. Carmel, CA: Hampton-Brown.

Twain, M. (1993 ed.). The adventures of Tom Sawyer. Essex, England: Longman Group UK Limited.

\section{REFERENCES}

[1] Berelson, B. (1952). Content analysis in communication research. New York: Hafner.

[2] Case, R. E., Ndura, E., \& Righettini, M. (2005). Balancing linguistic and social needs: Evaluating texts using a critical language awareness approach. Journal of Adolescent \& Adult Literacy, (48)5, 374-391. 
[3] Cohen, A. D. , \& Macaro, E. (2007). Language learner strategies: 30 years of research and practice. Oxford: Oxford University Press.

[4] Cohen, A. D., Weaver, S. J., \& Li, T-Y. (1996). The impact of strategies-based instruction on speaking a foreign language. Minneapolis: Center for Advanced Research on Language Acquisition, University of Minnesota.

[5] Dörnyei, Z. (2005). The psychology of the language learner: Individual differences in second language acquisition. Mahwah, NJ: Lawrence Erlbaum Associates.

[6] Dörnyei, Z., \& Ushioda, E. (Eds.). (2009). Motivation, language identity and the L2 self. Buffalo, NY: Multilingual Matters.

[7] Ehrman, M. E., Leaver, B. L., \& Oxford, R. L. (2003). A brief overview of individual differences in second language learning, System, 31, 313-330.

[8] Ellis, R. (2004). Individual differences in second language learning. In A. Davies \& C. Elder (Eds.), The handbook of applied linguistics (pp. 525-551). Oxford: Blackwell.

[9] George, A. (2009). Quantitative and qualitative approaches to content analysis. In K. Krippendorff and M. A. Bock (Eds.). The content analysis reader (pp. 144-155). Thousand Oaks, CA: Sage Publications, Inc.

[10] Gilmore, A. (2007). Authentic materials and authenticity in foreign language learning. Language Teaching, (40), 97-118.

[11] Grady, K. (1997). Critically reading an ESL text. TESOL Journal, (6) 4, 7-10.

[12] Hak, T., \& Bernts, T. (2009). Coder training: Explicit instruction and implicit socialization. In K. Krippendorff \& M. A. Bock (Eds.), The content analysis reader. (pp. 220-233). Thousand Oaks, CA: Sage Publications, Inc.

[13] Krippendorf, K. (2004). Content analysis: An introduction to its methodology (2 $2^{\text {nd }}$ ed.). Thousand Oaks, CA: Sage Publications, Inc.

[14] Liamputtong, P., \& Ezzy, D. (2005). Qualitative research methods. New York: Oxford University Press.

[15] Neuendorf, K. A. (2002). The content analysis guidebook. Thousand Oaks, CA: Sage Publications, Inc.

[16] O'Malley, J. M., \& Chamot, A. U. (1990). Language learning strategies in second language acquisition. Cambridge: Cambridge University Press.

[17] Orwig, C. (1999). Language learning strategies. Dallas: SIL International.

[18] Oxford, R. (1990). Language learning strategies: What every teacher should know. New York: Newbury House Publishers.

[19] Oxford, R. (1996). Language learning strategies around the world: Cross-cultural perspectives. Honolulu: University of Hawai'i Press.

[20] Oxford, R. (2001a). Language learning and styles and strategies. In M. Celce-Murcia (Ed.), Teaching English as a Second or Foreign Language ( $3^{\text {rd }}$ ed.) (pp. 359-366). Boston: Heinle \& Heinle.

[21] Oxford, R. (2001b). Language learning strategies. In R. Carter \& D. Nunan (Eds.), The Cambridge guide to teaching English to speakers of other languages (pp. 166-172). Cambridge: Cambridge University Press.

[22] Oxford, R. (in press). Upper Saddle River, NJ: Pearson.

[23] Piaget, J. P. (1971). Genetic epistemology. New York: W. W. Norton \& Co.

[24] Rivera-Mills, S. V., \& Plonsky, L. (2007). Empowering students with language learning strategies: A critical review of current issues. Foreign Language Annals, (40)3, 535-548.

[25] Weber, R. P. (1990). Basic content analysis ( $2^{\text {nd }}$ ed.). Newbury Park, CA: Sage Publications, Inc.

[26] White, C. (2008). Language learning strategies in independent language learning: An overview. In S. Hurd \& T. Lewis (Eds.), Language learning strategies in independent settings (pp. 3-24). Buffalo, NY: Multilingual Matters.

Jeffrey T. LaBelle has served as assistant professor in Marquette University's College of Education in Milwaukee, Wisconsin, since 2007. Prior to that time he taught for two years as assistant professor in the International and Multicultural Education Department of the University of San Francisco. Dr. LaBelle holds a BA in InterAmerican Studies with emphasis in Spanish and ESL from the University of the Pacific.

He completed his EdD in International and Multicultural Education from the University of San Francisco in 2005. His teaching and research interests focus on sociolinguistics, multicultural education, and immigrant English language acquisition. Fluent in Spanish for over 35 years, he previously taught ESL and Spanish at secondary schools in California and Peru. A Jesuit priest of the California province, he served in parish ministry for 12 years in San Jose, California, among Catholic immigrants from Mexico, Central America, Vietnam, and the Philippines. He has co-authored or co-edited three books: Pope John Paul II: A Reader (Paulist Press), Being Catholic in a Changing World (Paulist Press), and Seek God Everywhere: Reflections on the Spiritual Exercises of St. Ignatius Loyola (Doubleday). His current book project is titled Catholic Colleges in the $21^{\text {st }}$ Century: A Road Map for Campus Ministry (Paulist Press). 